\title{
Orchestrating Innovation Ecosystems: A Qualitative Analysis of Ecosystem Positioning Strategies
}

\author{
Katri Valkokari, Marko Seppänen, Maria Mäntylä, and Simo Jylhä-Ollila
}

\author{
(" Nothing is more difficult than the art of ") \\ maneuvering for advantageous positions. \\ Sun Tzu (544 BC - 496 BC) \\ Military general, strategist, and philosopher
}

\begin{abstract}
This article explores how firms can orchestrate innovation ecosystems to enhance collaboration for innovation among different actors. Most previous research on ecosystems has focused on firm-level strategies to operate in an ecosystem rather than the composition or orchestration of an ecosystem as a whole. However, finding the balance between the self-interests of involved actors is critical in order to create collaborative settings that induce different parties to jointly develop and put their best efforts into a joint endeavour. Thus, we undertook a qualitative study with 35 case companies from the metal and engineering industries, each of whom was interested in developing their position in ecosystems and improving their relational business practices. The findings suggest that there is an essential ecosystem competence that is needed by all actors in an ecosystem, regardless of their position, and that is the ability to manage dynamic strategic interactions related to innovation. This competence enables them to ensure the future vitality of the ecosystem and their own business. These results highlight the need for managers to profile their own company's role in an ecosystem in relation to the type of ecosystems, while simultaneously evaluating the ecosystem's ability and potential to survive.
\end{abstract}

\section{Introduction}

The importance of inter-organizational relationships and networks to innovation is widely acknowledged. And now, there is active discussion on the topic of value co-creation within boundary-spanning activities and various concepts related to collaborative innovation (Lee et al., 2012). Recent studies of such innovation practices underline a variety of different forms, such as inter-organizational alliances and collaborations with and within communities, crowds, or networks of individuals - including users, citizens, scientists, etc. However, although these perspectives deliver unique insights into specific distributed innovation processes, there are only limited connections across them (Bogers et al., 2016).

The notion of "ecosystems" offers an attractive metaphor to explore a variety of interactions and inter- linkages between multiple organizations in innovation (Autio \& Thomas, 2014). The metaphor emphasizes that the relationships are constantly co-evolving through actions and interactions of involved actors (Moore, 1996). In other words, inter-organizational relationships in ecosystems evolve through repetitive sequences of cooperation, conflict, and compromise, thereby altering positionings of actors and generating new roles (Pellikka \& Ali-Vehmas, 2016). Although ecosystems are a usual context for doing business in some industries, such as software and communication technologies (Muegge, 2013), research on ecosystems is underdeveloped and undertheorized (Spigel, 2017).

Ecosystems include broad sets of actors and, even in business ecosystems, the relationships and interactions are not always governed with contracts. This lack of formal structure increases the role of relational governance mechanisms (Poppo \& Zenger, 2002). As an 


\section{Orchestrating Innovation Ecosystems: A Qualitative Analysis of Ecosystem Positioning Strategies} Katri Valkokari, Marko Seppänen, Maria Mäntylä, and Simo Jylhä-Ollila

example, consider entrepreneurial or innovation ecosystems, which lack a clear power hierarchy or formalized enforcement methods that could impede informal interaction between firms (Bell et al., 2016; Pitelis, 2012). Thus, the key management issue in an ecosystem is setting the right balance between a shared vision and the self-interests of involved actors to influence, facilitate, and motivate their actions (Adner, 2006; Valkokari \& Valkokari, 2014). However, an ecosystem (as well as a network) is a multi-level phenomenon, which makes its orchestration challenging for a firm as a single entity. Still, the current research has focused more on firm-level strategies to operate in existing business ecosystems rather than their composing or orchestrating innovation ecosystems as a whole.

This article aims to bridge the gap by exploring how firms can orchestrate innovation ecosystems to enhance collaboration between different actors. Therefore, our research questions are:

1. What are the main roles of companies in their innovation ecosystems?

2. How should the actors collaborate by adopting particular roles?

We sought to answer these questions using a qualitative study of 35 companies and their ecosystem positioning strategies, with particular attention paid to the differences between well-established companies and startups. The context of our research is the mechanical engineering sector in Finland, which represents a quite traditional sector from the viewpoint of ecosystem thinking.

This article is organized as follows. First, we review the literature and then create a framework for ecosystem strategies in the innovation ecosystem context. Next, we present our research design and our results. Finally, we discuss our academic and managerial contributions.

\section{Background}

\section{Innovation and entrepreneurial ecosystems}

There has been and still is an enormous amount of scholarly attention paid to ecosystem typologies - and their differences and similarities. The innovation ecosystem approach has emphasized fostering the creation of growth, interaction, and innovative startups around so-called knowledge hubs (Engel \& Del-Palacio, 2011). Thus, a defining characteristic of innovation ecosystems is their ability to adapt and evolve (Basole, 2009).
For instance, Silicon Valley is often put forth as an example of a successful (local) innovation ecosystem where there are plenty of interactions and inter-linkages between multiple organizations. The innovation ecosystem concept is often utilized to highlight innovation emerging from the interaction between different actors or to differentiate them from national innovation systems and policies (Suominen et al., 2016). Similarly, entrepreneurial ecosystems have become a popular tool in the study of the geography of high-growth entrepreneurship (Spigel, 2017). From the company perspective, such innovation or entrepreneurial ecosystems may offer different learning possibilities according to their structure and participants Companies in the same industry or supply chain that serve the same larger customers learn from each other's production and service processes (Priore \& Sabel, 1984), whereas technology firms that have the same core technology share knowledge and networks related to new business opportunities (Spigel, 2017). Thus, in addition to growth-oriented SMEs and startups, regional innovation ecosystems need larger anchor companies close to the core in order to ensure connection to the global competition in business (Viitanen, 2016).

To sum up, in an innovation or entrepreneurial ecosystem, the focus is on creating new business opportunities or new knowledge, whereas a business ecosystem operates within the present business context and uses existing resources. In addition to companies, an innovation or entrepreneurial ecosystem may include many different actors, such as entrepreneurs, innovators, venture capitalists, accelerators, vendors, and academic institutions. For instance, in an innovation (or knowledge) ecosystem, the financial network that supports the actors (both companies and research institutes and other technology developers) has recently been identified as one of the key success factors (Clarysse et al., 2014). Regardless, established companies typically have their main focus on their current business ecosystems - even when building new solutions such as platforms (Evans \& Gawer, 2016).

For many companies, the attempt at ecosystem innovation has been a costly failure. This is because, along with new opportunities, innovation ecosystems also present a new set of risks (Adner, 2006). After all, firms are still interested in their own survival even if their ecosystem strategies should also consider how to increase the resilience of the whole ecosystem (Seppänen et al., 2015). Consequently, the concept of ecosystem resilience or health is "fuzzy", and it should be noted that ecosystem health (defined in natural ecosystems as a 


\section{Orchestrating Innovation Ecosystems: A Qualitative Analysis of Ecosystem Positioning Strategies} Katri Valkokari, Marko Seppänen, Maria Mäntylä, and Simo Jylhä-Ollila

state of ecosystem equilibrium) is not necessarily beneficial from the viewpoint of all involved actors (Valkokari, 2015). Thus, the previous literature has typically highlighted how the ecosystem leaders (i.e., organizations in central leadership positions) should take care of ecosystem health (Iansiti \& Levien, 2004).

\section{Ecosystem borders}

In present-day business, ecosystems are global and setting an ecosystem's borders is complicated - or even impossible (Iansiti \& Levien, 2004). Still, studies of innovation ecosystems as well as entrepreneurial ecosystems have often neglected this global dimension and focused on actors that are regional or geographically proximate (Valkokari, 2015) or have examined national innovation systems (Suominen et al., 2016). Thus, the borders of innovation ecosystem are even fuzzier than the borders of business ecosystem given that they are more dynamic, with actors, roles, and interlinkages changing constantly (Valkokari et al., 2016). Hence, the most recent innovation studies point out that discussions about closed national innovation systems are rather factitious: new innovations are actually generated in global settings (Viitanen, 2016; Oksanen \& Hautamäki, 2015). If an innovation ecosystem is to be defined more extensively - by more than business relationships or national borders - one of the key challenges is determine how it can be formed through shared sense-making and by the cognitive construction of the ecosystem participants, (in line with the cognitive model of strategic groups introduced by Reger and Huff (1993). However, it should be noted that companies' strategies related to collaboration within innovation often are more typically emergent than deliberate (Mintzberg \& Waters, 1985).

Since Chesbrough's (2003) seminal work on open innovation, the need for openness and collaboration in innovation has been highlighted through numerous concepts such as "collaborative innovation", "democratized innovation", "open innovation", "networked innovation", and "co-innovation", as summarized by Lee and colleagues (2012). Although open innovation has received broad acceptance since its initial launch over a decade ago, there is undoubtedly more work to be done. Open innovation was initially understood and implemented as a series of collaborations between two organizations to open up the internal innovation process. Today, however, we may see multiple cases in which the concept is being used to orchestrate many players across manifold roles in the innovation process. Put simply, designing and managing innovation communities will become more and more important to the future of open innovation (Chesbrough, 2012). According to this new model of open innovation, company boundaries are becoming more permeable, enabling resources to increasingly flow into and out of the firm at various stages of the innovation funnel (Lee et al., 2012: Bogers et al., 2016; Zobel, 2016). Recent studies present inconsistent results regarding the outcomes of open innovation, suggesting positive, curvilinear, and even negative associations between openness and innovation performance measures at the company level. These heterogeneous empirical findings call for an explanation of the interfirm differences in benefiting from external sources of innovation and how organizations implement open innovation in ecosystems in which all participants are depending on each other in co-evolving their capabilities and innovation outcomes (Bogers et al., 2016). Nevertheless, there is a gap in understanding of how companies are able to translate their openness into innovation outcomes and whether - and if so, how - companies can create a competitive edge in product innovation by utilizing these external sources (Zobel, 2016).

In addition to changing in space, ecosystems borders also change in time, and the innovation ecosystem lifecycle spans the time from the discovery of a new technology until the first successful commercialization of that technology (Dedehayir \& Seppänen, 2015). Similarly, Moore (1993) has identified four lifecycle phases in an ecosystem: birth, expansion, leadership, and self-renewal (or death). And Adner (2012) suggests that there are five levers of reconfiguration: relocation (of actors); separation (of tasks to be undertaken by different actors); combination (of separate tasks); addition (of new actors to undertake tasks that would benefit the ecosystem); and subtraction (of existing actors and their tasks to benefit the ecosystem). To summarize, ecosystem management can be divided into composing and orchestration tasks (Valkokari \& Valkokari, 2014). Thus, the composing phase - how ecosystems come into existence in the first place - has received scarce attention (Dedehayir \& Seppänen, 2015), and discussion of ecosystem management has focused on orchestrating business ecosystems. Furthermore, orchestration has been conceived as a function performed by one actor, designated for instance as a keystone (Iansiti \& Levien, 2004), an ecosystem leader (Adner, 2012), or an ecosystem coordinator (Jansen \& Cusumano, 2013). Still, perspectives on innovation-ecosystem strategy, such as co-creation, networking, and interaction with innovation ecosystem partners, play a crucial role in an individual company's success given that companies are increasingly dependent on their collaborators (Pellikka \& Ali-Vehmas, 2016). 


\section{Orchestrating Innovation Ecosystems: A Qualitative Analysis of Ecosystem Positioning Strategies} Katri Valkokari, Marko Seppänen, Maria Mäntylä, and Simo Jylhä-Ollila

\section{Ecosystem strategies}

The choice of ecosystem strategy is affected both by a firm's intentions, strategic thinking, and current position in an ecosystem. Iansiti and Levien (2004) have identified three (business) ecosystem strategies that a firm can choose: keystone, dominator, or niche. These strategies are strongly linked with the actors' positions within the network structure, which can be central or peripheral. According to network scholars, a central position in a network has a positive influence on an actors' own innovativeness, for instance through access to different knowledge sources (Zaheer \& Bell, 2005). However, the three roles of "feeder", "breeder", and "niche", as identified by Zahra and Nambisan (2011), highlight that the attitudes of actors lean more towards ecosystem co-evolution than their own strategic positioning. These authors also acknowledged that the roles are typical manifestations and hybrids of those that exist in a wide variety of companies. Furthermore, Muegge (2011) has identified different innovation ecosystem roles of technology-intensive business organizations as adopters and patrons of open platforms, and stewards and promoters of innovation communities. In addition to the key roles played by financiers and sponsors, the discussion of entrepreneurial ecosystems also highlights the important role of mentors (Ozgen \& Baron, 2007; Lafuente et al., 2007) and dealmakers (Feldman \& Zoller, 2012).

Most of the above-mentioned roles and also their contingent strategies can be linked to the network position of the company. The keystone, dominators, patrons, promoters, feeders, as well as breeders act as a hub, whereas niche firms, stewards, and adopters are typically in the position of spokes. Consequently, other kinds of organizations, in addition to companies, operate in some of the roles, for example as financiers, sponsors, mentors, and dealmakers, and their network positions are less clear. A hub often provides a single face for the customer and operates as an ecosystem orchestrator whereas the spokes represent complementary actors that provide the services, technological solutions, and other assets distributed across various settings. Thus, the actor's network position and role are dependent on other actors' strategies and actions, and they are therefore constantly changing (Pellikka \& AliVehmas, 2016). In other words, the ecosystem is coevolving all the time and a niche player may eventually become a keystone in a new emerging ecosystem. Furthermore, a given actor may play different roles in the different ecosystems to which they belong (Iansiti \& Levien, 2004).

\section{Preliminary research framework}

In line with strategy in general, the ecosystem strategy should answer the questions of where to compete, when to compete, and how to compete (Adner, 2006). On the other hand, success in an ecosystem requires a new kind of strategic thinking - concurrent collaboration and competition (Zahra \& Nambisan, 2011). Furthermore, through an ecosystem strategy, companies should consider interdependency and complementary resources in their business as well as their own capabilities to integrate these external resources and knowledge (Iansiti \& Levien, 2004).

Based on the above-mentioned characteristics of ecosystem strategies and in order to highlight the need for collaborative innovation in the ecosystem, we have built our preliminary research framework prior to data collection. The framework has two dimensions answering the questions of how and where to collaborate (Figure 1). The first dimension (the $\mathrm{x}$-axis) explores the "where" question (i.e., where to set the borders for an ecosystem) and the second dimension (the y-axis) considers the "how" question (i.e., how the actors should collaborate by adopting particular roles). The question of where to set the ecosystem borders represents a continuum from local to global ecosystems. The question of how to collaborate represents a continuum of ecosystem roles extending from the hub (i.e., owner, keystone, promoter) out to the spokes (i.e., adopters, niche firms, stewards). Most studies consider a snapshot of ecosystem strategies of one firm at one point in time, rather

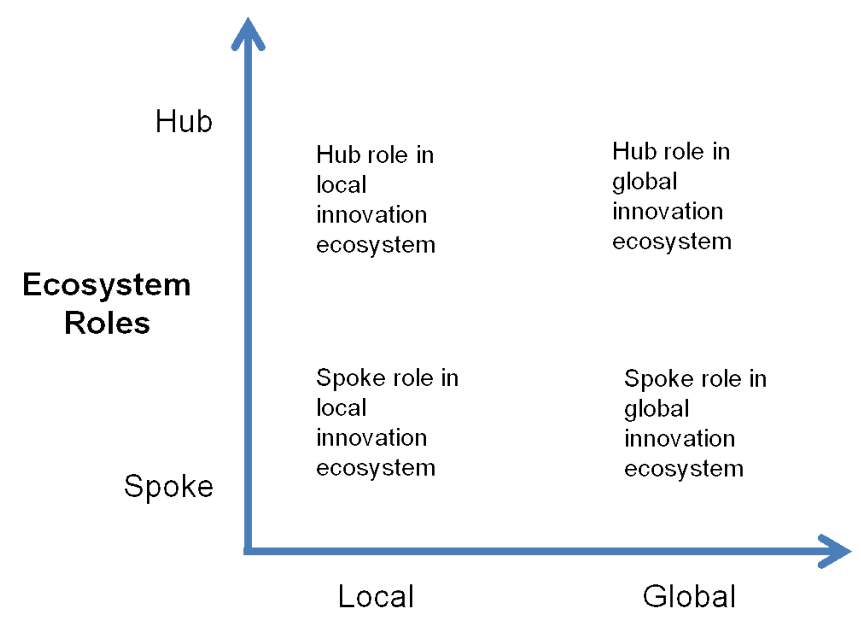

Ecosystem Borders

Figure 1. A preliminary research framework on ecosystem strategies 


\section{Orchestrating Innovation Ecosystems: A Qualitative Analysis of Ecosystem Positioning Strategies} Katri Valkokari, Marko Seppänen, Maria Mäntylä, and Simo Jylhä-Ollila

than exploring the interdependency of evolving strategic choices in their context, in other words, within the ecosystem (West \& Wood, 2008). Although the co-evolution of an ecosystem is an important characteristic and is strongly linked with the "when to compete" question (Adner, 2006), this perspective is quite case-specific, and therefore we focused on the two viewpoints of "where" and "how".

In practice, ecosystem strategies or even memberships in ecosystems are not necessarily obvious to firms; their ecosystem positioning strategies are more emerging than intentional (Mintzberg \& Waters, 1985). Instead, firms typically see their networks and other inter-organizational relationships from their own perspectives rather than emphasizing ecosystem-level viewpoints (Valkokari, 2014). Moreover, ecosystems as well as networks are multi-level phenomena, which makes it difficult to manage them as a single entity. Furthermore, companies' ecosystem roles and congruent strategies are often hybrids.

\section{Research Design}

In this study, the choice of method was motivated by our desire to deepen and enrich our understanding of innovation ecosystems in supporting the strategic choices of companies. The research was conducted as a qualitative analysis, as it was seen best to fit in line with the research questions. In qualitative research, the chosen sample needs to be purposeful (Eisenhardt, 1989; Miles \& Huberman, 1994) and therefore we integrated a data total of 35 case companies from the metal and engineering industries. The selected companies were all interested in developing their ecosystem roles and relational business practices. By selecting a rather traditional industry sector such as the Finnish mechanical engineering sector, we also aimed to look beyond the "hype" of the ecosystem concept. With this dataset, we compared ecosystem strategies between startups (21 cases, 1-21) and well-established large companies (14 cases, A-N). In order to ensure richness of data, we selected a dataset that represented these two groups, which are, according to Viitanen (2016), the main groups of private actors that operate in innovation ecosystems.

\section{Data collection and analysis}

The practical challenge of innovation ecosystem orchestration and the identification of theoretical typologies of ecosystem strategies and their characteristics were the starting points of the research. Tables 1 and 2 summarize the case data sources of ecosystem views in the startups (Table 1) and in the established companies (Table 2). In subclassifying both the startups and established companies by size, we used the definition provided by the European Commission, (2015):

1. Micro- or small companies employ fewer than 50 persons and their annual turnover or annual balance sheet total does not exceed EUR 10 million

2. Medium-sized companies employ fewer than 250 persons and either have an annual turnover that does not exceed EUR 50 million or they have an annual balance sheet not exceeding EUR 43 million

The majority of the startups were micro-companies with less than EUR 2 million in annual turnover and balance sheet total and less than 10 employees, except two of them that were classified as small companies. The established companies were mostly medium-sized or large companies and only one of them was a small company with less than 250 employees.

The empirical material was collected by a group of 6 researchers (including the authors of this article), who interviewed a total of 65 managers from 21 startups and 14 established companies. Each interview lasted between 1 and 1.5 hours. Semi-structured themed interviews were chosen as the main source of empirical material because the study was partly explorative in nature and the meanings of concepts needed to be negotiated with the interviewees. The interview themes follow the dimensions of the preliminary research framework and included questions about innovation ecosystem and networks, their borders (global versus local), and the company's roles and strategies within ecosystems. All of the interviews were conducted in Finnish. The interviewees in the established companies occupied senior corporate, R\&D and business unit, or customer and supplier relationship management positions, whereas the interviewees with the startups were typically founders or CEOs. The interview material was complemented by secondary data such as company presentations.

Analysis of the empirical material proceeded by applying the grounded theory approach. Open coding, "the process of breaking down, examining, comparing, conceptualising and categorising data" (Strauss \& Corbin, 1990), was applied to the empirical material. The coding process created concepts that were later grouped and categorized, which enabled comparisons between the datasets from established companies and startups. Based on the coding, quotations characterizing the companies' ecosystem perspectives were collected and 


\section{Orchestrating Innovation Ecosystems: A Qualitative Analysis of Ecosystem Positioning Strategies Katri Valkokari, Marko Seppänen, Maria Mäntylä, and Simo Jylhä-Ollila}

Table 1. Summary of cases from startups

\begin{tabular}{|c|c|c|c|}
\hline Company & Role & Size & Representatives \\
\hline 1 & Equipment manufacturer & Micro & - Founder and CEO \\
\hline 2 & Equipment manufacturer & Small & - Founder and CEO \\
\hline 3 & Equipment manufacturer & Micro & - Founder and CEO \\
\hline 4 & Equipment manufacturer & Micro & - Founder and CEO \\
\hline 5 & Equipment manufacturer & Micro & - Founder and CEO \\
\hline 6 & Equipment manufacturer & Micro & $\begin{array}{l}\text { - Founder, sales, marketing } \\
\text { - Product developer }\end{array}$ \\
\hline 7 & Equipment manufacturer & Micro & - Founder and CEO \\
\hline 8 & Equipment manufacturer & Micro & - Founder and CEO \\
\hline 9 & Equipment manufacturer & Micro & - Founder \\
\hline 10 & Equipment manufacturer & Micro & - Founder and CEO \\
\hline 11 & Equipment manufacturer & Small & $\begin{array}{l}\text { - } \quad \text { Founder and CEO } \\
\text { - } \quad \text { Production manager }\end{array}$ \\
\hline 12 & Equipment manufacturer & Micro & - Founder and CEO \\
\hline 13 & Equipment manufacturer & Small & - Founder and CEO \\
\hline 14 & Equipment manufacturer & Micro & - Founder and CEO \\
\hline 15 & Equipment manufacturer & Micro & - Founder and CEO \\
\hline 16 & Equipment manufacturer & Micro & - Founders (2) \\
\hline 17 & Equipment manufacturer & Micro & - Founder and CEO \\
\hline 18 & Equipment manufacturer & Micro & $\begin{array}{l}\text { - Founder and CEO } \\
\text { - Salesman }\end{array}$ \\
\hline 19 & Equipment manufacturer & Micro & - Founder and CEO \\
\hline 20 & Equipment manufacturer & Micro & - Founder and CEO \\
\hline 21 & Equipment manufacturer & Micro & - Founder and CEO \\
\hline
\end{tabular}




\section{Orchestrating Innovation Ecosystems: A Qualitative Analysis of Ecosystem Positioning Strategies} Katri Valkokari, Marko Seppänen, Maria Mäntylä, and Simo Jylhä-Ollila

Table 2. Summary of cases from established companies

\begin{tabular}{|c|c|c|c|}
\hline Company & Role & Size & Representatives \\
\hline A & Brand owner & Medium & $\begin{array}{l}\text { - Top management } \\
\text { - Middle management }\end{array}$ \\
\hline B & Service provider & Large & - Middle management \\
\hline $\mathrm{C}$ & Manufacturer (material supplier) & Large & - Top management \\
\hline $\mathrm{D}$ & Solution provider & Large & - Middle management and experts (6) \\
\hline $\mathrm{E}$ & Brand owner & Large & - Middle management and experts (4) \\
\hline F & Service provider & Small & - Middle management \\
\hline G & Solution provider & Medium & - Top management \\
\hline $\mathrm{H}$ & Solution provider & Large & - Middle management \\
\hline I & Solution provider & Large & - Middle management and experts (6) \\
\hline $\mathrm{J}$ & Brand owner & Medium & - Top management \& middle management (3) \\
\hline $\mathrm{K}$ & Subcontractor & Medium & - Middle management \\
\hline $\mathrm{L}$ & Solution provider & Large & - Middle management (3) \\
\hline M & Brand owner & Medium & - Middle management (6) \\
\hline $\mathrm{N}$ & Brand owner & Medium & - Top \& middle management (5) \\
\hline
\end{tabular}

the most relevant ones were chosen to be presented in this article. Then, the researchers who had conducted the interviews positioned the companies in the preliminary research framework (Figure 1). The positioning was based on shared guidelines. Along the $\mathrm{x}$-axis, the share of global revenue and geographical position of markets and customers guided the positioning. Along the y-axis, network role (i.e., the business model) of the companies directed the mapping.

Next, we highlight typical perspectives on ecosystems through various quotations, then the positionings of startup and established companies are presented and discussed.

\section{Case Findings}

The interviews revealed that companies' views about ecosystems differ significantly, and thereby both their resources and capabilities to orchestrate ecosystems were different. Even so, all 35 of the case companies reported engaging in having collaborative relationships to develop new innovations and look for new sources of competitive advantage.

Making sense of ecosystems

Although most of the interviewees were familiar with the concept of ecosystems, only a few of the established companies $(\mathrm{B}, \mathrm{C}, \mathrm{D}, \mathrm{H}$, and $\mathrm{I})$ reported that they had actively considered their own a strategy or approach. In other words, the ecosystem strategies of the interviewed companies were more emergent than deliberate. The firms - especially the well-established companies - were typically thinking more about the business than innovation activities. Furthermore, attempts to intentionally influence other actors (i.e., through ecosystem orchestration) were uncommon. Still, deviating examples could be found, as represented by the following quotation from the sourcing manager of company D: "Operating in ecosystems means that your role is dynamically changing from customer to technology provider and that you have to concurrently collaborate and compete. So, we have to think about our strategic position all the time." 


\section{Orchestrating Innovation Ecosystems: A Qualitative Analysis of Ecosystem Positioning Strategies} Katri Valkokari, Marko Seppänen, Maria Mäntylä, and Simo Jylhä-Ollila

The startups in particular perceived themselves as independent actors, as emphasized by the founder of company 16: "We are more of an independent actor. Well, we're actually producing very little - we're more like creating our own ecosystem network for the world." Also, the importance of social networks was highlighted by the startups, who highlighted that key actors consist mostly of the entrepreneur's own personal relations, including family (case 3), neighbours (case 8), friends from school (case 5), colleagues from a previous firm (case 9), industry connections (case 17), or contacts related to a research project (case 10).

In the well-established companies, there was typically a long history of different relationships and, in addition to business actors, the representatives mentioned a broad list of other ecosystem actors, from regulators and politicians to members of local communities. The following quotation from company $\mathrm{H}$ provides a good example of the complexity of connections needed: "We are in a field in which it is not enough to collaborate with a paying customer, but to come into contact with legislators and authorities, when developing new solutions. Customers often need funding and we have to participate in such discussion with the World Bank etc. Finally, at the project site, communication with the local community is needed to understand their expectations and needs. There is a sacred tree that needed to be appreciated, and the social dimensions are important."

Few representatives of the startup companies acknowledge the larger business environment - or even the innovation ecosystem - around them, as this example from company 13 shows: "But it [the ecosystem] can change, or it is living. Let's say it [the company] is not firmly there in its own place - we have to [be part of an ecosystem], we do not have money to produce everything ourselves." The large well-established companies typically recognized the broader business (or innovation) ecosystem around them.

Still, hardly any of the large companies had an explicitly intentional approach in their development related to an innovation ecosystem. One diverging example was a representative of company $\mathrm{C}$, who highlighted their role as a network promoter: "We have been building $a$ Western Finland business cluster and contacted some other manufacturing companies (interviewee mentions companies in other industrial sectors...) to make the change on-going." Another example of intentional building of new ecosystem partnerships was mentioned by the representative of company B: "We are negotiating our role as a system integrator in a triad aiming to provide solutions to big global players."

Additionally, within the startup companies, there were some examples of an intentional approach to the utilization of ecosystems as a source of external knowledge, as noted by the interviewee from company 5: "We were looking at what we do not have and what we need more of. We were looking at who we have in the social circle." On the other hand, related to the possibility of utilizing external knowledge, the established companies highlighted the need to understand the company and customers' specific needs, as illustrated by a representative from company E: "External actors in the innovation ecosystem must be able to understand our solution from the viewpoint of our customers, and even the customer's customers' needs. The product must be suitable for our world - it must be anchored into a certain way of life, maintenance, etc.."

To sum up, when discussing key network dimensions, a small number of startups identified their supplier networks (cases 8 and 9), their startup network (case 1), and their industry forums or intermediaries (case 12). In the established companies, the interviewees typically mentioned all these networking dimensions, although the interviewee's own role might have focused on one of the relationship types. Regarding the collaboration between startups and the large established companies, the representative of company B stated how their mindsets differ and how the management of intellectual property is therefore a key challenge: "Startups want to work with us, but they also say openly that they give the same rights to all possible partners in order to access to the new markets."

\section{Summary of cases}

As described above, the case companies differed in their ecosystem activities and especially in the extent to which they intentionally operate in different ecosystems. Still, we were able to locate all the cases in our framework according to the main focus of their ecosystem strategies at the time of study. Figure 2a locates the startups, Figure 2b locates the well-established companies, and Figure 3 locates all 35 case companies together.

According to the interview material, 17 startups out of 21 are seen as global actors who clearly have an objective of operating in global markets and increasing worldwide sales, therefore not only focusing on the domestic market. In a few cases, the volume of exports was even 


\section{Orchestrating Innovation Ecosystems: A Qualitative Analysis of Ecosystem Positioning Strategies} Katri Valkokari, Marko Seppänen, Maria Mäntylä, and Simo Jylhä-Ollila

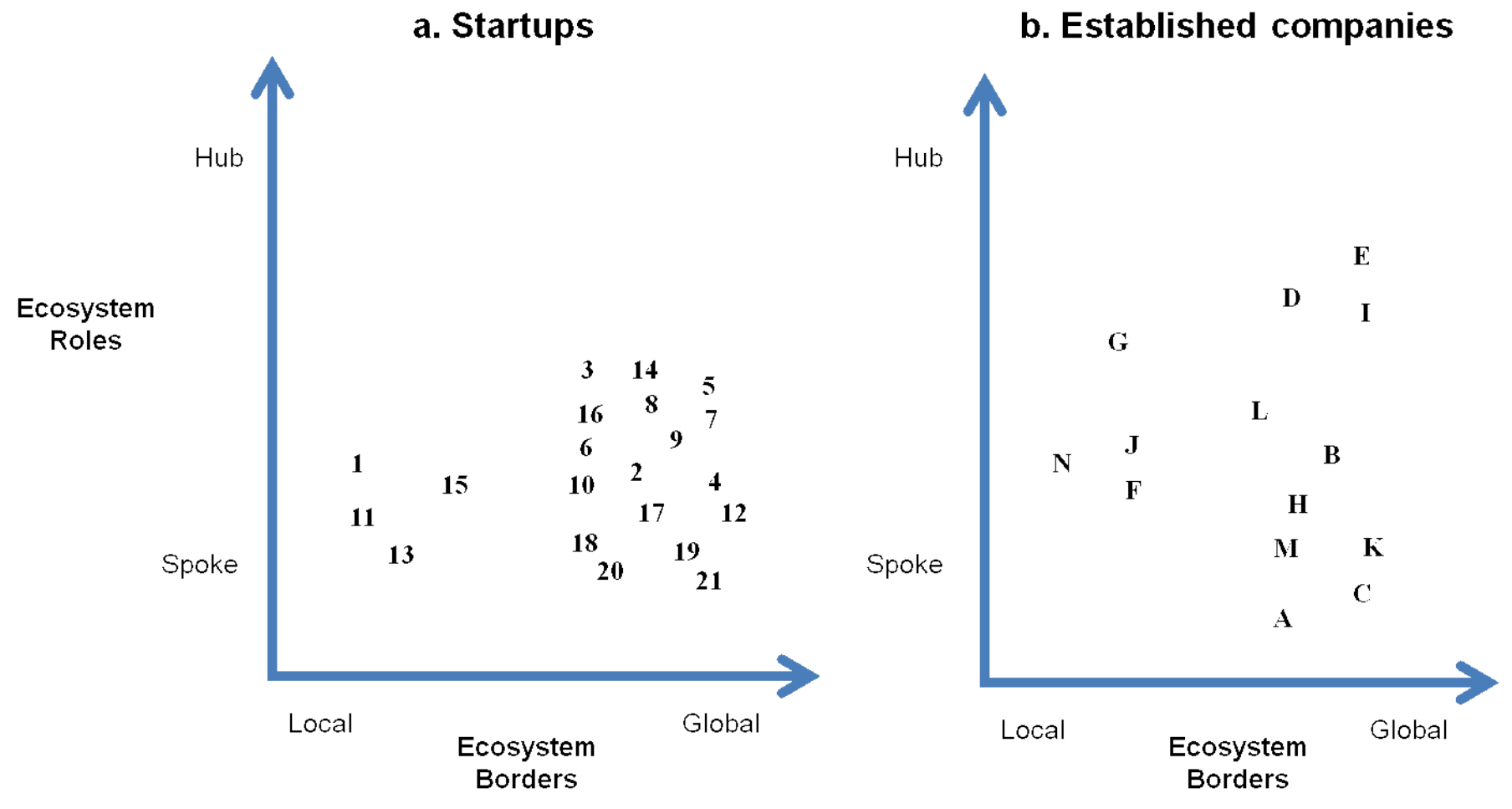

Figure 2. The 21 startup case companies (a) and the 14 established case companies (b) located in the ecosystem strategies research framework

larger than that of domestic trading. Due to scarce resources, startups typically operated in one or two international markets and therefore the "global" dimension differs from the global ecosystem activities of the established companies. Only four startups are located in the local part of the framework depicted in Figure 2a. Their business activities and collaboration between other stakeholders took place mainly at the local level and there was no solid intention to broaden the innovation activities globally. All companies had quite a restricted impression of the ecosystem surrounding the company. Instead of being an owner/promoter and having an established position in the ecosystem, many startups are seen in steward/adopter/niche roles, focusing on their own needs and operations. Given that all the companies located in this framework are fairly young startups, they may not have fully established their positions in their innovation ecosystems.

Only a few of the globally operating established companies (E, D, and I) have a central role in their innovation ecosystems at the global level (Figure 2b). Six of the established companies (A, C, D, H, I, and $\mathrm{K}$ ) belong to a large, globally operating corporation and therefore their innovation activities also have global perspectives. Thus, their activities are often based on internal $R \& D$ cooperation between business units in different countries. Typically, these companies were operating as technology providers. Within the small and mediumsized companies (F, J, and $\mathrm{N}$ ), the network roles were similar and the local dimension was even stronger.

Discussion and comparison between the companies Both the descriptive quotations and the qualitative analysis of the companies' positioning advance our understanding of ecosystem strategies in startups and well-established companies, along with their perspectives of innovation ecosystem orchestration in different roles. Figure 3 summarizes the positions of all 35 case companies.

There were some differences between startups and wellestablished companies, although most of them are positioned at the bottom-right corner of the framework, or the "spoke role in global innovation ecosystem" as depicted in Figure 1. The well-established companies typically highlighted their operations in different network dimensions; the startups typically did not see that they would be part of any existing ecosystem and instead envision themselves as players in emerging new ecosystems. In summary, the qualitative analysis of the ecosystem strategies in the 35 case companies provides 


\section{Orchestrating Innovation Ecosystems: A Qualitative Analysis of Ecosystem Positioning Strategies} Katri Valkokari, Marko Seppänen, Maria Mäntylä, and Simo Jylhä-Ollila

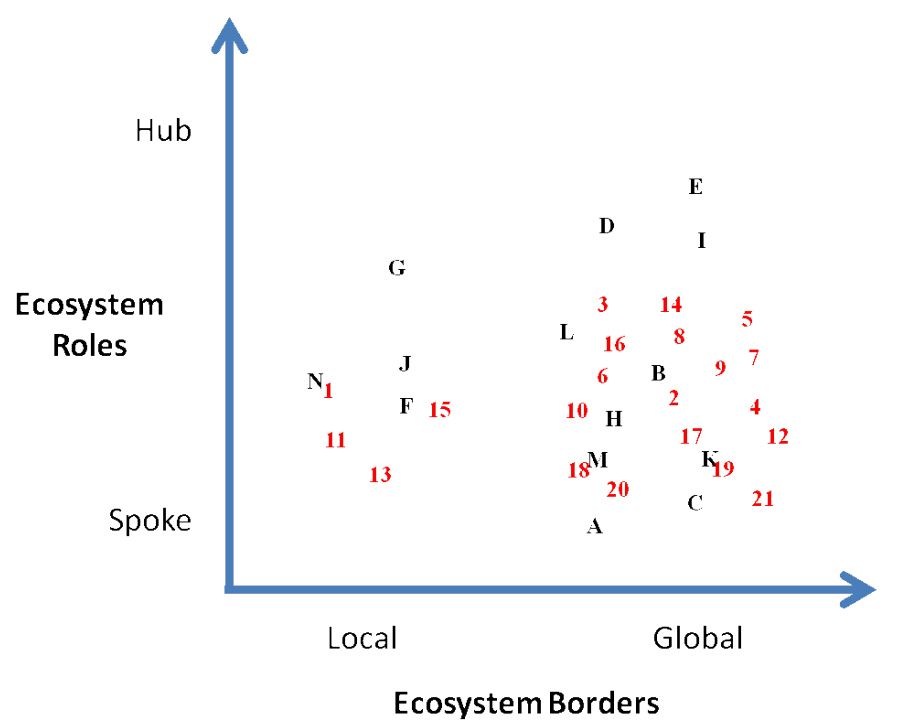

Figure 3. All 35 case companies located in the ecosystem strategies research framework

answers to the research questions as follows. First, with regards to the main roles companies play in their innovation ecosystems, we found that spoke roles (i.e., adopters, niche firms, stewards) are typical among companies in the Finnish mechanical engineering sector and that these companies were generally operating on a global scene related to their innovation ecosystems. This finding highlights the global dimension and is in line with the most recent discussions on innovation ecosystems (Viitanen, 2016), but challenges the former literature on innovation or entrepreneurial ecosystems. Second, regarding orchestration, we found that the established companies focused more on orchestration in existing business ecosystems but that the startups more typically saw their role in composing future ecosystems. Furthermore, the roles were often seen as hybrids, and most of the companies consider that their actions may influence the future development paths of an ecosystem and its health, which complements the previous literature.

\section{Conclusions and Practical Implications}

The aim of this article was to explore how firms can orchestrate innovation ecosystems to enhance different actors' collaboration for innovation. Based on the empirical data, the ecosystem strategies of the Finnish mechanical engineering sector companies seem to be rather traditional and technology-oriented. In the present-day global business environment, most of the companies considered their innovation ecosystem global, although setting the ecosystem borders was judged to a complic- ated issue. Until now, studies of innovation as well as entrepreneurial (eco)systems have typically omitted this global dimension and focused on regional - and geographically proximate - actors (Suominen et al., 2016; Valkokari, 2015; Viitanen, 2016). Therefore, our findings are in line with recent research of inter-organizational innovation highlighting crowdsourcing and digital platforms as means to identify novel and distant sources for knowledge inflows by broadcasting particular tasks to a larger undefined network of potential external problem solvers (i.e., the "crowd"). When operating on such large geographical scales, for instance when exclusively using digital platforms, the levels of interaction and collaboration between the ecosystem actors may remain low, and further research on new ways to integrate global and local playgrounds - as well as physical and virtual innovation settings - is required.

Firm-centric strategies too often end in "winner-takesall" settings in ecosystems. Therefore, our findings highlight that a new kind of thinking by all involved actors is needed in order to share the value for all members in an ecosystem and thereby ensure the health of the ecosystem. To a certain extent, this view challenges the previous literature (Iansiti \& Levien, 2004), which has pointed out that the ecosystem leader should take care of ecosystem health. Furthermore, within their strategic thinking, companies should consider how they are perceived by other actors. One way to survive and succeed in the innovation ecosystem is to be an attractive collaboration partner. And, based on our empirical findings, that perception should be a main concern in most of the Finnish mechanical engineering companies, as they were more often positioned in "spoke" rather than "hub" roles.

The results of collaborative innovation in ecosystems appear from the dynamics of strategic maneuvering among actors. Therefore, the key success factor, and an ecosystem competence, is a company's ability to manage dynamic strategic interactions related to innovation. Furthermore, these strategic intentions are not often explicitly pointed out and the orchestration then requires interaction and constant follow-up in order to get a clear picture of these actions. This understanding provides managerial implications in the utilization of innovation ecosystems and profiling of both the company's own role and the type of ecosystem, while simultaneously assisting them in evaluating the ecosystems' ability and potential to survive. To sum up, this view could help managers to better understand how (in which role) and where (with local and global settings) to collaborate for innovation. 


\section{Orchestrating Innovation Ecosystems: A Qualitative Analysis of Ecosystem Positioning Strategies} Katri Valkokari, Marko Seppänen, Maria Mäntylä, and Simo Jylhä-Ollila

As with any research effort, this one also has its limitations, some of which offer possible avenues for future research. First, due to the qualitative design with 35 cases and the innovation ecosystem being the main unit of analysis, it was not possible to give deeper consideration to entrepreneurship and strategic management at the company level. Still, the case examples demonstrate that the role of managers and entrepreneurs in the orchestration of innovation is challenging.

\section{About the Authors}

Katri Valkokari is a Research Manager at VTT Technical Research Centre of Finland in the Business, Innovation and Foresight research area. Over the past 15 years, she has carried out several development projects concerning different networked business arrangements (ecosystems, networks, partnerships, and firms). In 2009, Katri completed her doctoral thesis on business network development. She has published several international and national articles in the research areas of business network management, collaboration, organizational knowledge, and innovation management.

Marko Seppänen, $\mathrm{PhD}$, is Vice Dean for Education at the Faculty of Business and Built Environment, and is a Full Professor in the field of industrial management at Tampere University of Technology, Finland. He is an expert in managing value creation in business ecosystems, business concept development, and innovation management. In his latest research, he has examined platform-based competition in business ecosystems and innovation management in business networks. His research has appeared in high-quality peer-reviewed journals such as the Journal of Product Innovation Management, Technological Forecasting and Social Change, the Journal of Systems and Software, and the International Journal of Physical Distribution \& Logistics Management.
Therefore, one important subject for future studies would be to research entrepreneurship and to undertake a longitudinal study of an ecosystem from composition to orchestration through to the strategic choices of all involved actors. Second, all of the case companies operated in the same industry sector (mechanical engineering). Further research on other contexts could either validate the study results or provide interesting complementary views on the topic.

Maria Mäntylä (MSc Admin) is a Research Scientist at VTT Technical Research Centre of Finland in the Innovations, Economy \& Policy team. She obtained her master's degree in Local and Regional Governance from the University of Tampere, Finland, in 2015. She also studied Social Sciences of Sport in the University of Jyväskylä, Finland. Maria has been involved in various national and international research projects regarding innovation research, especially in the area of regional innovation systems. She is currently writing her doctoral thesis on sports technologies and innovation ecosystems at the University of Tampere.

Simo Jylhä-Ollila (MSc Tech) is an Analyst in Elisa Corporation's Industrial IoT department. He holds a master's degree in Industrial Engineering and Management from Tampere University of Technology, Finland. Previously, he worked as a research assistant in Tampere University of Technology and worked in Elisa's research team before moving into his current position in the company. 


\section{Orchestrating Innovation Ecosystems: A Qualitative Analysis of Ecosystem Positioning Strategies Katri Valkokari, Marko Seppänen, Maria Mäntylä, and Simo Jylhä-Ollila}

\section{References}

Adner, R. 2006. Match Your Innovation Strategy to Your Innovation Ecosystem Match Your Innovation Strategy to Your Innovation Ecosystem. Harvard Business Review, 84(4): 98-107.

Adner, R. 2012. The Wide Lens: A New Strategy for Innovation. New York, NY: Portfolio/Penguin.

Autio, E., \& Thomas, L. D. W. 2014. Innovation Ecosystems: Implications for Innovation Management. In M. Dodgson, D. M. Gann, \& N. Phillips (Eds.), Oxford Handbook of Innovation Management: 204-228. Oxford: Oxford University Press. http://dx.doi.org/10.1093/oxfordhb/9780199694945.013.012

Basole, R. C. 2009. Visualization of Interfirm Relations in a Converging Mobile Ecosystem. Journal of Information Technology, 24(2): 144-159. http://dx.doi.org/10.1057/jit.2008.34

Bell, S. J., Tracey, P., Heide, J. B., \& Bell, S. I. 2016. The Organization of Regional Clusters. The Academy of Management Review, 34(4): 623-642.

Bogers, M., Zobel, A., Afuah, A., Almirall, E., Dahlander, L., Frederiksen, L., Gawer, A., Haefliger, S., Hagedoorn, J., Hilgers, D., Laursen, K., Magnusson, M. G., Majchrzak, A., McCarthy, I. P., Moeslein, K. M., Nambisan, S., Piller, F. T., Radziwon, A., Rossi-, C., Sims, J., \& Ter Wal, A. L. J. 2016. The Open Innovation Research Landscape: Established Perspectives and Emerging Themes across Different Levels of Analysis. Industry and Innovation, 24(1): 8-40. http://dx.doi.org/10.1080/13662716.2016.1240068

Chesbrough, H. 2003. Open Innovation: The New Imperative for Creating and Profiting from Technology. Boston: Harvard Business School Press.

Chesbrough, H. 2012. Open Innovation: Where We've Been and Where We're Going. Research-Technology Management, 55(4): 20-27. http://dx.doi.org/10.5437/08956308X5504085

Clarysse, B., Wright, M., Bruneel, J., \& Mahajan, A. 2014. Creating Value in Ecosystems: Crossing the Chasm between Knowledge and Business Ecosystems. Research Policy, 43(7): 1164-1176. http://dx.doi.org/10.1016/j.respol.2014.04.014

Dedehayir, O., \& Seppänen, M. 2015. Birth and Expansion of Innovation Ecosystems: A Case Study of Copper Production. Journal of Technology Management \& Innovation, 10(2): 145-153. http://dx.doi.org/10.4067/S0718-27242015000200010

Eisenhardt, K. M. 1989. Building Theories from Case Study Research. Academy of Management Review, 14: 532-550. http://dx.doi.org/10.5465/AMR.1989.4308385

Engel, J. S., \& Del-Palacio, I. 2011. Global Clusters of Innovation: The Case of Israel and Silicon Valley. California Management Review, 53(2): $27-49$.

http://dx.doi.org/10.1525/cmr.2011.53.2.27

European Commission. 2015. User Guide to the SME Definition. Luxembourg: Publications Office of the European Union.

Evans, P. C., \& Gawer, A. 2016. The Rise of the Platform Enterprise: A Global Survey. New York: The Center for Global Enterprise.

Feldman, M., \& Zoller, T. D. 2012. Dealmakers in Place: Social Capital Connections in Regional Entrepreneurial Economies. Regional Studies, 46(1): 23-37.

http://dx.doi.org/10.1080/00343404.2011.607808
Iansiti, M., \& Levien, R. 2004. The Keystone Advantage: What the New Dynamics Of Business Ecosystems Mean for Strategy, Innovation, and Sustainability. Boston: Harvard Business School Press.

Jansen, S., \& Cusumano, M. A. 2013. Defining Software Ecosystems: A Survey of Software Platforms and Business Network Governance. In S. Jansen, S. Brinkkemper, \& M. A. Cusumano (Eds.), Software Ecosystems: Analyzing and Managing Business Networks in the Software Industry: 13-28. Cheltenham, UK: Edward Elgar.

Lafuente, E., Vaillant, Y., \& Rialp, J. 2007. Regional Differences in the Influence of Role-Models: Comparing the Entrepreneurial Process of Rural Catalonia. Regional Studies, 41(6): 779-795.

Lee, S. M., Olson, D. L., \& Trimi, S. 2012. Co-Innovation: Convergenomics, Collaboration, and Co-Creation for Organizational Values. Management Decision, 50(5): 817-831. http://dx.doi.org/10.1108/00251741211227528

Miles, M. B., \& Huberman, A. M. (Eds.). 1994. Qualitative Data Analysis: An Expanded Sourcebook (2nd ed.). London: Sage Publications.

Mintzberg, H., \& Waters, J. A. 1985. Of Strategies, Deliberate and Emergent. Strategic Management Journal, 6(3): 257-272. http://dx.doi.org/10.1002/smj.4250060306

Moore, J. F. 1993. Predators and Prey: A New Ecology of Competition. Harvard Business Review, 71(3): 75-86.

Moore, J. F. 1996. The Death of Competition: Leadership and Strategy in the Age of Business Ecosystems. New York, NY: Harper Business.

Muegge, S. 2011. Business Ecosystems as Institutions of Participation: A Systems Perspective on Community-Developed Platforms. Technology Innovation Management Review, 1(2): 4-13. http://timreview.ca/article/495

Muegge, S. 2013. Platforms, Communities, and Business Ecosystems: Lessons Learned about Technology Entrepreneurship in an Interconnected World. Technology Innovation Management Review, 3(2): 5-15.

http://timreview.ca/article/655

Oksanen, K., \& Hautamäki, A. 2015. Sustainable Innovation: A Competitive Advantage for Innovation Ecosystems. Technology Innovation Management Review, 5(10): 24-30.

http://timreview.ca/article/934

Ozgen, E., \& Baron, R. A. 2007. Social Sources of Information in Opportunity Recognition: Effects of Mentors, Industry Networks, and Professional Forums. Journal of Business Venturing, 22(2): 174-192. http://dx.doi.org/10.1016/j.jbusvent.2005.12.001

Pellikka, J., \& Ali-Vehmas, T. 2016. Managing Innovation Ecosystems to Create and Capture Value in ICT Industries. Technology Innovation Management Review, 6(10): 17-24. http://timreview.ca/article/1024

Pitelis, C. 2012. Clusters, Entrepreneurial Ecosystem Co-Creation, and Appropriability: A Conceptual Framework. Industrial and Corporate Change, 21(6): 1359-1388. http://doi.org/10.1093/icc/dts008

Poppo, L., \& Zenger, T. 2002. Do Formal Contracts and Relational Governance Function as Substitutes or Complements? Strategic Management Journal, 23(8): 707-725.

http://dx.doi.org/10.1002/smj.249

Priore, M. J., \& Sabel, C. F. 1984. The Second Industrial Divide: Possibilities for Prosperity. New York, NY: Basic Books. 


\section{Orchestrating Innovation Ecosystems: A Qualitative Analysis of Ecosystem Positioning Strategies Katri Valkokari, Marko Seppänen, Maria Mäntylä, and Simo Jylhä-Ollila}

Reger, R. K., \& Huff, A. S. 1993. Strategic Groups: A Cognitive Perspective. Strategic Management Journal, 14(2): 103-123. http://dx.doi.org/10.1002/smj.4250140203

Seppänen, M., Dedehayir, O., Still, K., Valkokari, K., \& Suominen, A. 2015. Platform Competences to Enhance Network Effects in Business Ecosystems. In Proceedings of the 2015 ISPIM Innovation Summit, Brisbane, Australia, December 6-9. London: The International Society for Professional Innovation Management.

Spigel, B. 2017. The Relational Organization of Entrepreneurial Ecosystems. Entrepreneurship Theory and Practice, 41(1): 49-72. http://doi.wiley.com/10.1111/etap.12167

Strauss, A. L., \& Corbin, J. 1990. Basics of Qualitative Research: Grounded Theory Procedures and Techniques. London: Sage Publications.

Suominen, A., Seppänen, M., \& Dedehayir, O. 2016. Innovation Systems and Ecosystems: A Review and Synthesis. In Proceedings of the 2016 ISPIM Innovation Conference, Porto, Portugal, June 19-22. London: The International Society for Professional Innovation Management.

Valkokari, K. 2015. Business, Innovation, and Knowledge Ecosystems: How They Differ and How to Survive and Thrive within Them. Technology Innovation Management Review, 5(8): 17-24. http://timreview.ca/article/919

Valkokari, K., Amitrano, C. C., Bifulco, F., \& Valjakka, T. 2016. Managing Actors, Resources, and Activities in Innovation Ecosystems - A Design Science Approach. In H. Afsarmanesh, L. Camarinha-Matos, \& A. Lucas Soares (Eds), Collaboration in a Hyperconnected World. PRO-VE 2016. IFIP Advances in Information and Communication Technology, vol 480. Cham, Switzerland: Springer. http://dx.doi.org/10.1007/978-3-319-45390-3_44
Valkokari, K., \& Valkokari, P. 2014. How SMEs Can Manage Their Networks - Lessons Learnt from Communication in Animal Swarms. International Journal of Inspiration Economy, 1(1): $111-128$.

Viitanen, J. 2016. Profiling Regional Innovation Ecosystems as Functional Collaborative Systems: The Case of Cambridge. Technology Innovation Management Review, 6(12): 6-25. http://timreview.ca/article/1038

West, J., \& Wood, D. 2008. Creating and Evolving an Open Innovation Ecosystem: Lessons from Symbian Ltd. SSRN eLibrary. http://dx.doi.org/10.2139/ssrn.1532926

Zaheer, A., \& Bell, G. G. 2005. Benefiting from Network Position: Firm Capabilities, Structural Holes, and Performance. Strategic Management Journal, 26(9): 809-825. http://dx.doi.org/10.1002/smj.482

Zahra, S. A., \& Nambisan, S. 2011. Entrepreneurship in Global Innovation Ecosystems. Academy of Marketing Science (AMS) Review, 1(4). http://dx.doi.org/10.1007/s13162-011-0004-3

Zobel, A.-K. 2016. Benefiting from Open Innovation: A Multidimensional Model of Absorptive Capacity. Journal of Product Innovation Management. http://doi.wiley.com/10.1111/jpim.12361 